\title{
EXPANSIÓN URBANA Y TURISMO EN LA COMARCA DEL CAMPO DE CARTAGENA-MAR MENOR (MURCIA). IMPACTO EN EL SELLADO DEL SUELO
}

\author{
Asunción Romero Díaz \\ Agustín Caballero Pedraza \\ Alfredo Pérez. Morales \\ Universidad de Murcia
}

\section{RESUMEN}

En las últimas décadas, la comarca estudiada ha experimentado una expansión urbana sin precedentes motivada por el turismo residencial. Esto ha supuesto un notable impacto medioambiental. Para estudiar este proceso y sus impactos, se han analizado los tipos de viviendas y población, digitalizando las superficies urbanas de tres fechas (1956, 1981 y 2011) y estimando la longitud y superficie de la red viaria. La superficie de suelo sellada, por este tipo de usos se ha evaluado en un $16 \%$ con respecto al total. Consecuencia de lo anterior es el aumento en la frecuencia de las inundaciones.

Palabras clave: urbanismo expansivo, turismo, sellado del suelo, inundaciones, sureste de España.

\section{Urbanisation and tourism in the Campo Cartagena-Mar Menor area (Murcia, Spain). Impact on soil sealing}

\section{ABSTRACT}

In recent decades, the region studied has experienced a significant urban expansion driven by the residential tourism. This resulted in a considerable environmental impact. To

Recibido: 14 de julio de 2015

Devuelto para su revisión: 3 de noviembre de 2015

Aceptado: 15 de enero de 2016

Departamento de Geografía. Universidad de Murcia. Campus de La Merced. 30001 MURCIA (España). E-mail: arodi@um.es; acp29398@um.es; alfredop@um.es 
study this process and its impacts, we have analyzed the types of housing and population, urban surfaces digitized in three dates (1956, 1981 and 2011) and estimated the length and surface of the road network. The soil surface sealed by this type of use was evaluated in $16 \%$ of the total. Consequence of this is the increased frequency of flooding.

Keywords: expansive urban planning, tourism, soil sealing, floods, southeast of Spain.

\section{INTRODUCCIÓN}

\subsection{El cambio en la actividad turística}

La llamada "burbuja inmobiliaria" (1998-2007) de la costa mediterránea de España, en la que se localiza la Región de Murcia, ha producido un enorme "urbanismo expansivo", consecuencia, en parte, de la demanda de migrantes jubilados procedentes mayoritariamente del norte de Europa. Son numerosos los autores que han abordado el tema de la inmigración de este colectivo a España atraídos, entre otras cosas, por el clima: King et al. (2000); O’Reilly (2009); Williams et al. (2000); Rodríguez et al. (2005); Casado (2006); Huete (2009); Mazón et al. (2009); o Huete y Mantecón (2013). Así, el número de este tipo de nuevos habitantes retirados empadronados en España se multiplicó por 7,5 entre 1991 y 2012 (Membrado Tena, 2015). Una gran mayoría de ellos (95\%) eligió para pasar sus años de jubilación, las regiones españolas litorales de clima mediterráneo, entre las que se encuentra la Comarca del Campo de Cartagena Mar Menor (CCCMM).

En las últimas décadas, en algunas áreas del Mediterráneo español, el clásico "turismo de sol y playa" dio paso al "turismo residencial", que ofrece como principal atractivo una mejora en la calidad de vida de los que lo practican. Ello fue debido al desarrollo del Estado de Bienestar europeo y al envejecimiento de la población de la UE. El turismo residencial ha transformado de forma radical el paisaje de gran parte de las costas españolas. Este tipo de turismo puede suponer, en un principio, mejoras en las economías locales, debido al incremento de puestos de trabajo en la construcción e industrias relacionadas, así como un aumento de impuestos para los ayuntamientos correspondientes; pero en la actualidad, se está viendo otra serie de inconvenientes, que a priori no se predijeron.

Estas comarcas que solían ser tradicionalmente focos de emigración, se convirtieron en áreas muy atractivas para la inmigración, por motivos laborales para unos, y en busca de una mayor calidad de vida, para otros. No obstante, este modelo de desarrollo turístico no está exento de problemas y limitaciones. La ausencia de planificación y su rápida extensión espacial ha provocado, por un lado, un fuerte impacto ambiental y, por otro, no ha generado una estructura turística de calidad (en cuanto a servicios e infraestructuras) que facilitase futuras medidas de recuperación o reconversión turística (Aledo et al., 2007). Con la crisis económica, el crecimiento económico inicial para las administraciones ha cesado y, en la actualidad, los ayuntamientos apenas pueden proporcionar los servicios básicos a estas urbanizaciones. 
Algunas de las consecuencias medioambientales negativas que el urbanismo expansivo, realizado sin la adecuada planificación, ha traído consigo son: cambios en los usos del suelo (IGN 2006; Burriel, 2008; Gaja, 2008; Romero, 2010; Rullán, 2011); destrucción del paisaje; escasez de agua en las regiones con déficit hídrico (Vera Rebollo, 2006); o sellado artificial de los suelos (Docampo Calvo, 2011; Romero Díaz et al., 2011), con el consiguiente incremento del riesgo de inundaciones (Pérez Morales et al., 2015).

La comarca que se analiza en este estudio constituye una de las zonas turísticas más importante de la Región de Murcia, con singularidades naturales y muchas potencialidades de ocio y recreación (salud, deportes, etc.) (García Sánchez et al., 2002). Además, constituye un área donde la segunda residencia tuvo una especial expansión en el Mar Menor desde mediados de los años setenta del siglo pasado (Figura 2), debido al "boom inmobiliario" y, como ha ocurrido en todo el Mediterráneo español, con importantes impactos medioambientales.

\subsection{La expansión urbana y el sellado del suelo}

El sellado del suelo es uno de los efectos más visibles de las presiones que sufre el suelo a consecuencia del desarrollo humano. Entre los efectos más importantes de este proceso de artificialización se encuentran: la pérdida de superficie fértil, la fragmentación de la biodiversidad y la disminución de la capacidad de infiltración del agua (Pérez Morales et al., 2016).

La importancia del sellado del suelo fue puesto de manifiesto en el año 2002, en la Comunicación de la Comisión al Parlamento Europeo (Comité Económico y Social y al Comité de las Regiones), titulada "Hacia una estrategia temática para la protección del suelo" (COM/2002/0179 final), estando por primera vez entre los ocho tipos principales de degradación o amenazas que afectan a al territorio europeo: (1) Sellado del suelo; (2) Erosión; (3) Pérdida de materia orgánica; (4) Pérdida de biodiversidad; (5) Contaminación del suelo; (6) Compactación del suelo; (7) Salinización; y (8) Riesgos hidrogeológicos por inundaciones y deslizamientos de tierras.

Los mayores impactos, relacionados con el sellado, tienen lugar en países en los que se ha producido un importante desarrollo de infraestructuras como viviendas, servicios, carreteras, etc. En la Europa occidental, se ha detectado un importante incremento del sellado como consecuencia del aumento de la población en los núcleos urbanos y la influencia de demanda turística en determinadas regiones y zonas costeras, sobre todo en la costa mediterránea (Membrado Tena, 2015).

Según el Perfil Ambiental de España 2005 (MMA, 2006), en los últimos 14 años las áreas artificiales (especialmente en las zonas urbanas), han crecido más que en la media europea. De acuerdo a estos datos, el incremento de la superficie urbanizada es prácticamente el doble en el período de 1990-2000, es decir, mientras que en la UE con un incremento de la población del 3,5\%, el crecimiento de la superficie urbanizada ha sido del 13,8\%, en España, con un incremento de la población del 4,3\%, el aumento de la superficie urbanizada ha alcanzado el 25,4\%. Las razones pueden encontrarse en el cambio del modelo de ciudad, cada vez más extensiva con una mayor ocupación del suelo por viviendas unifamiliares y un crecimiento de infraestructuras de transporte con la consiguiente fragmentación del territorio (MMA, 2006). 
Con el incremento de las zonas urbanas y la construcción de nuevas vías de comunicación (ambas asfaltadas e impermeabilizadas), se produce un incremento de suelos sellados. Se reduce la infiltración del agua en el suelo, disminuyendo la recarga natural de los acuíferos, la conservación de los humedales o la diversidad biológica. La destrucción de la cubierta natural del suelo y su impermeabilización modifica sustancialmente el proceso de la escorrentía y según Crespí et al. (2007) hace aumentar, al mismo tiempo, las superficies que corren riesgo de sufrir inundaciones.

\subsection{Objetivos}

El objetivo general de este estudio ha sido analizar las consecuencias que la expansión urbana y el turismo ha tenido en el sellado del suelo en la Comarca del Campo de Cartagena Mar Menor (CCCMM) en las últimas décadas.

Como objetivos específicos son de citar: (1) el análisis de la tipología de viviendas y la población nacional y extranjera en la comarca como consecuencia de la influencia del turismo en la misma mediante datos de carácter estadísticos; (2) la evaluación de las superficies urbanas en años de referencia (1956, 1981 y 2011) en cada uno de los municipios estudiados mediante digitalización de ortofotos; (3) la realización de una cartografía de sellado del suelo, consecuencia de la acción antrópica; y (4) el efecto medioambiental que el sellado tiene en las inundaciones.

\section{2. ÁREA DE ESTUDIO}

La CCCMM, situada en el sureste de la Región de Murcia (Figura 1), constituye una amplia planicie vertiente al Mar Menor. Según la propuesta de comarcas aprobada por el Consejo Regional de Murcia en 1980, en ella estarían incluidos los municipios de San Pedro del Pinatar, San Javier, Los Alcázares y Torre Pacheco; aunque para este estudio se han incluido también las áreas vertientes al Mar Menor de los municipios de Murcia y Cartagena. Con la excepción del municipio de Murcia y Torre Pacheco todos tienen litoral en la laguna del Mar Menor.

Desde un punto de vista geológico, el área de estudio se inscribe en el ámbito de las Cordilleras Béticas y está enmarcada por una orla de sierras de mediana altitud: sierra de Cartagena-La Unión al Sur; sierras de Carrascoy, del Puerto, Villares, Columbares, Altaona y Escalona al Norte; Sierra de Las Victorias al Oeste; y la Laguna Salada del Mar Menor, al Oeste. El clima mediterráneo semiárido, se caracteriza por recibir escasas precipitaciones (en torno a $300 \mathrm{~mm}$ anuales), aunque con una alta irregularidad y, en ocasiones, de alta intensidad. Las temperaturas son suaves en invierno y elevadas en verano, con una media anual de $17^{\circ} \mathrm{C}$. El número medio de horas de sol al año se sitúa en 3.000 (Romero Díaz y Belmonte Serrato, 2011).

La comarca no posee ningún cauce de agua permanente, debido a la escasa elevación de sus relieves circundantes, la extrema aridez del clima y la ausencia de cursos de agua alógenos. No obstante, posee numerosas ramblas (habitualmente secas) que, en ocasiones, consecuencia de precipitaciones intensas, pueden llevar mucha agua y causar inundaciones (Romero Díaz et al., 2011). Los cambios de usos del suelo actuales han favorecido su frecuencia e intensidad. 
La actividad económica de la CCCMM se debe, principalmente, al turismo y la agricultura. El turismo se concentra en torno al Mar Menor (términos municipales de Cartagena, Los Alcázares, San Javier y San Pedro del Pinatar, mientras que la actividad agraria se extiende por todo el Campo de Cartagena, afectando principalmente, a los municipios de Fuente Álamo, Torre Pacheco, norte de Cartagena, sur de Murcia y, en menor medida, a Los Alcázares, San Javier y San Pedro del Pinatar (González Ortiz, 2007). Tradicionalmente, la aridez de esta comarca reduce mucho las posibilidades de actividad agraria, pese a ello, el hombre ha puesto en regadío una gran superficie con agua extraída del subsuelo mediante artilugios tradicionales (norias, aceñas y molinos de viento) primero, y motores eléctricos después (Román Cervantes, 2007). Hoy el trasvase Tajo-Segura ha transformado profundamente las posibilidades agrarias de la comarca al paliar, en gran medida, la escasez de agua de la comarca, y ha contribuido a la recuperación de los acuíferos sobreexplotados (Martínez Menchón y Senent Alonso, 2007).

\section{Figura 1 \\ LOCALIZACIÓN DEL ÁREA DE ESTUDIO}

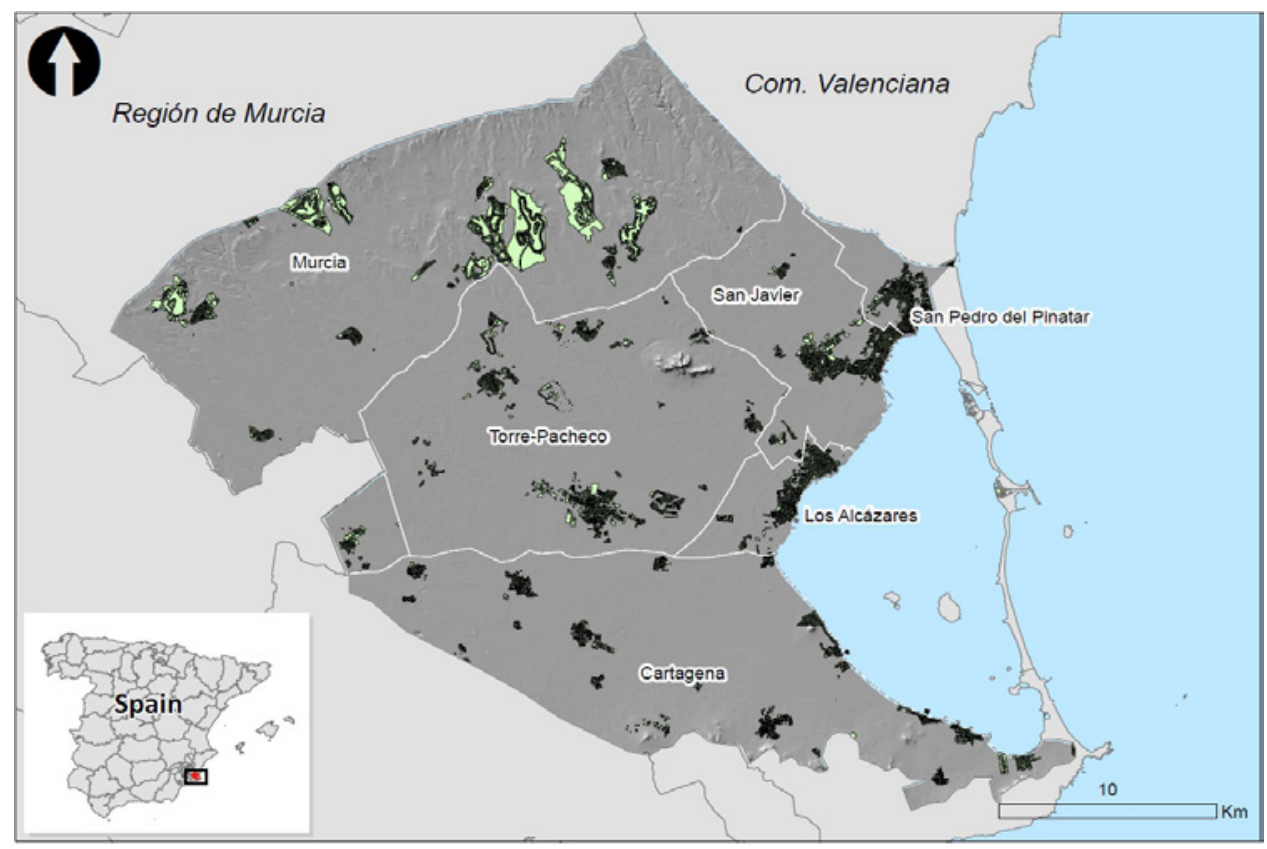

Fuente: elaboración propia.

\section{METODOLOGÍA Y FUENTES}

Para la digitalización de las ortofotos se ha utilizado el mosaico de ortofotos contenido en Cartomur, el Portal Digital del Servicio de Cartografía de la Dirección General de Ordenación del Territorio de la Región de Murcia. El tratamiento de la Información 
Geográfica (SIG), se ha realizado mediante el programa gvSIG. Las fechas de las ortofotos analizadas han sido 1956, 1981 y 2011. Las imágenes de 1956 se corresponden con las primeras imágenes disponibles, y las de 1981 y 2011 son dos vuelos de buena resolución con un intervalo de 24 y 30 años respectivamente. Además 2011 coincide con el último censo de población y viviendas.

Los datos estadísticos se han obtenido de los anuarios de la Región de Murcia (CREM) y del Instituto Nacional de Estadística.

La información sobre áreas inundables procede del Sistema Nacional de Cartografía de Zonas Inundables del MAGRAMA y con ella se ha realizado un análisis del número de inmuebles construidos en zona inundable según diferentes periodos de retorno (PR10, PR50, PR100 y PR500).

Para la red de carreteras se empleó la información digital libre contenida en Open Street Map mediante su descarga a través del plugin de OSM en QGIS 2.2. Al tratarse de una cobertura de tipo lineal, hubo que realizar un reclasificación por tipos de anchura según el tipo de vía y el posterior cálculo de áreas de influencia para la medida de superficies.

También se han realizado numerosas visitas al campo para verificar sobre el terreno algunos de los aspectos estudiados.

\section{RESULTADOS Y DISCUSIÓN}

\subsection{Tipo de viviendas y población en la CСCMM}

Respecto al conjunto de viviendas, al comparar los dos últimos censos disponibles de 2001 y 2011 (INE, 2013), la Región de Murcia ocupa el primer puesto en crecimiento del número de viviendas por CCAA con $31,1 \%$, y el cuarto puesto si se consideran las provincias. Y uno de los municipios aquí estudiados, Torre Pacheco, es el tercer municipio de España, mayor de 20.000 habitantes, con mayor crecimiento relativo en número de viviendas entre 2001 y 2011 , con un $115,5 \%$.

Para esta investigación, en el análisis de viviendas realizado se han excluido los municipios de Cartagena y Murcia, pues si bien parte de su superficie se incluye en la comarca, no así las ciudades de Murcia y Cartagena, en donde se concentra la mayor parte de la población, lo que podría introducir una importante distorsión estadística.

\subsubsection{Viviendas secundarias}

Uno de los hechos que refleja la influencia del turismo residencial es el número de viviendas secundarias. En el año 2011 (fecha del último censo de población y viviendas) las viviendas secundarias en la Región de Murcia representaban el 20\% del total, frente al 14,6\% de España (INE, 2013). Según los datos disponibles, desde 1950, se observa una evolución creciente hasta la actualidad (Figura 2). Entre las décadas de los años 70 y 90 del siglo XX se dio un crecimiento muy rápido propiciado por el boom turístico nacional e internacional, consecuencia de la bonanza económica vivida en esos años. Así, entre 1986 y 1992 tuvo lugar la llamada "burbuja inmobiliaria" (especulación en el mercado de bienes inmuebles en España) que duró hasta finales de 2007 o principios de 2008, fecha de inicio 
de la actual crisis económica española. Como resultado de ese periodo expansionista, a partir de la década de los 90 y primeros años del siglo XXI, el crecimiento de este tipo de viviendas, en general, se ralentiza, aunque no de igual modo en todas las regiones.

Figura 2

\section{EVOLUCIÓN DE LAS VIVIENDAS SECUNDARIAS EN LA REGIÓN DE MURCIA (1950-2011)}

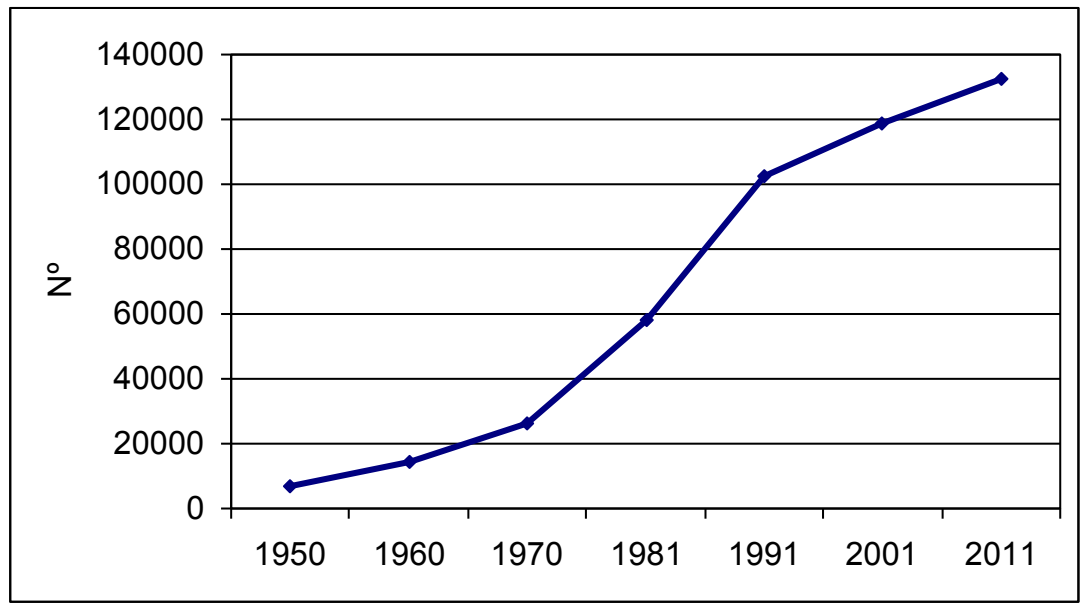

Fuente: elaboración propia a partir de datos del INE.

Es de reseñar, como gran parte de las viviendas segundarias de la Región de Murcia (el 63,7\%) se concentran en los municipios estudiados. Destacan los ribereños del Mar Menor: San Javier, Los Alcázares y San Pedro del Pinatar como los que mayor número de viviendas secundarias tienen en la actualidad (Figura 3).

Tomando como referencia los dos últimos censos elaborados, uno con anterioridad a la crisis económica (2001) y otro con posterioridad (2011), es posible observar (Tabla 3) como, en términos absolutos (Figura 3), sólo en el municipio de Los Alcázares disminuyó la construcción de viviendas secundarias. En términos relativos (Figura 4), los porcentajes que corresponden a este tipo de viviendas respecto a las viviendas principales disminuyeron en Los Alcázares y San Javier; mientras que, por el contrario, se incrementaron en San Pedro del Pinatar y Torre Pacheco, destacando San Pedro del Pinatar en donde el porcentaje de variación fue superior al $19 \%$.

A fecha de 2011, pese al descenso señalado, la vivienda secundaria tiene una enorme importancia en la comarca, destacando valores del $70 \%$ en Los Alcázares (81\% en 2001), $59 \%$ en San Javier (71\% en 2001) y 45\% en San Pedro del Pinatar (Figura 4). No obstante, hay que mencionar que gran parte del porcentaje de San Javier no se localiza en el sector del municipio correspondiente a la ribera interior del Mar Menor, sino al sector de La Manga del Mar Menor que corresponde a este municipio. 
Figura 3

NÚMERO DE VIVIENDAS SECUNDARIAS EN LA CCCMM.

AÑOS 2001 Y 2011

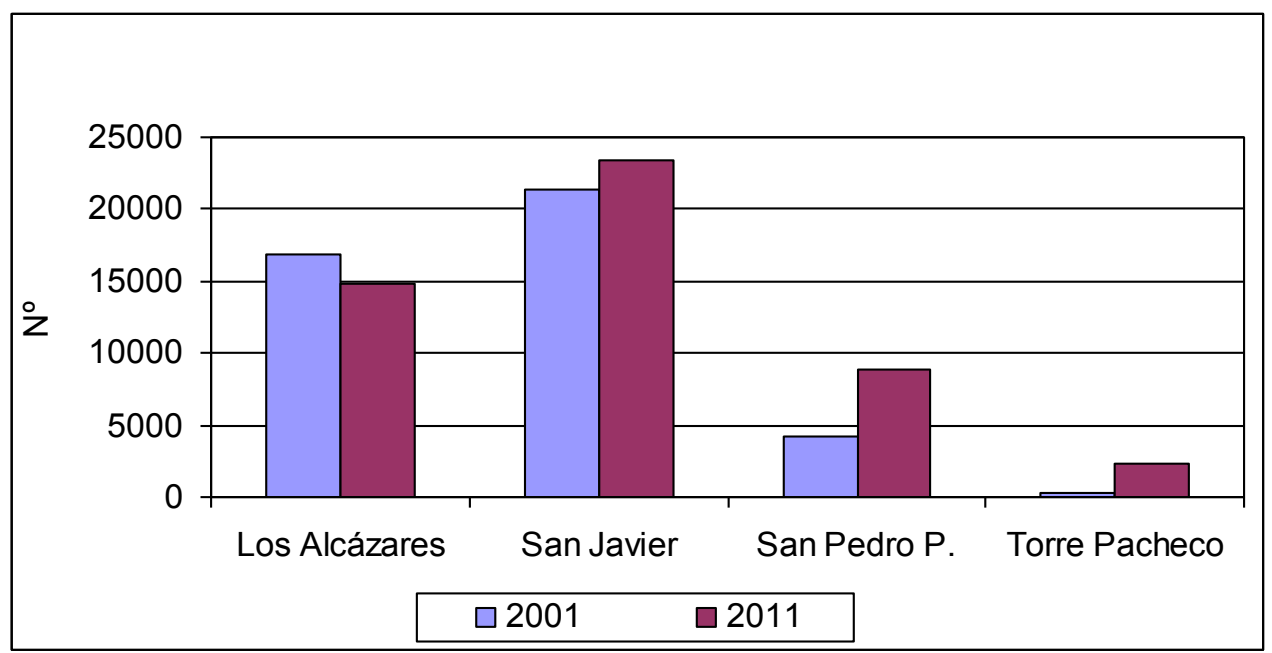

Fuente: elaboración propia a partir de datos del INE.

Figura 4

VIVIENDAS SECUNDARIAS (\%) RESPECTO

A LAS VIVIENDAS TOTALES. AÑOS 2001 Y 2011

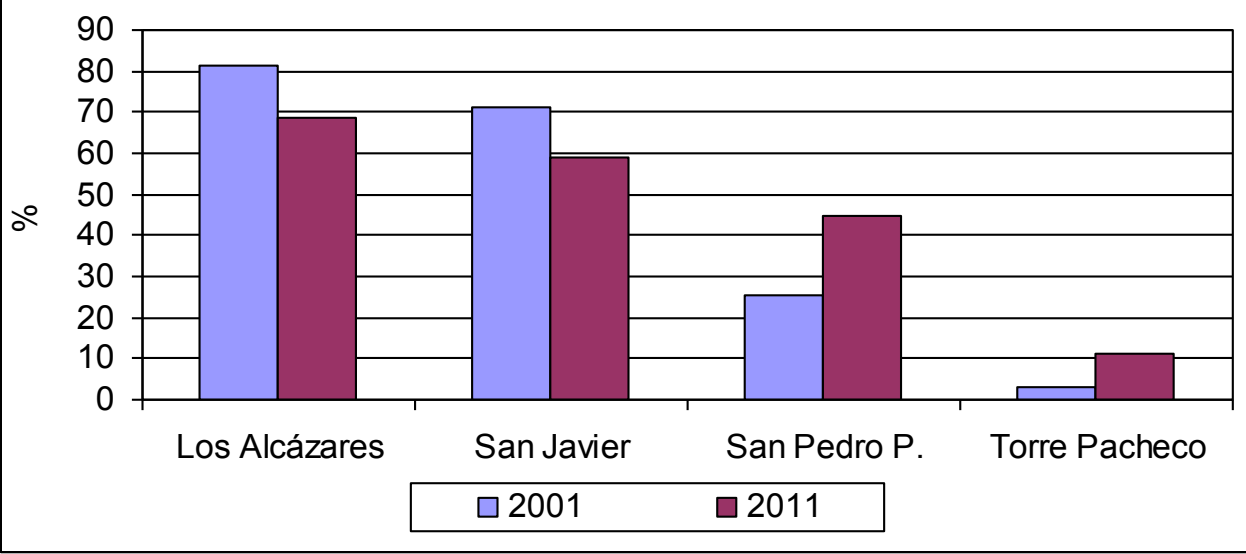

Fuente: elaboración propia a partir de datos del INE. 


\subsubsection{Viviendas vacías}

Un tercer tipo de viviendas de interés para el estudio del fenómeno de la expansión urbana, lo constituyen las vacías. Estas, en la mayoría de los casos, son fruto de una construcción especulativa (unida a la burbuja inmobiliaria) y la posterior crisis económica. Según un informe del INE (2013), el número de viviendas de este tipo en España aumentó en una década (2001-2011) el 10,8\%, siendo Galicia, la Rioja y Murcia las comunidades autónomas con mayores porcentajes de crecimiento. En 2011 las de la Región de Murcia ascendían a 129.111, de las que el 48\% (62.458), se encontraban en la comarca analizada. A escala local, para dar una idea de la relevancia de este fenómeno constructivo en el área de estudio, el municipio de toda España, mayor de 20.000 habitantes, con mayor porcentaje de viviendas vacías $(35,9 \%)$ era Torre Pacheco (INE, 2013).

Tabla 1

NÚMERO Y \% DE VIVIENDAS VACÍAS EN LA CCCMM

\begin{tabular}{|l|c|c|c|c|}
\hline \multirow{2}{*}{ Municipio } & $\begin{array}{c}\mathbf{N}^{\mathbf{0}} \text { Viviendas } \\
\text { Vacías }\end{array}$ & $\begin{array}{c}\mathbf{N}^{\mathbf{0}} \text { Viviendas } \\
\text { Vacías }\end{array}$ & $\begin{array}{c}\text { \% Viviendas } \\
\text { Vacías }\end{array}$ & $\begin{array}{c}\text { \% Viviendas } \\
\text { Vacías }\end{array}$ \\
\cline { 2 - 5 } & $\mathbf{2 0 0 1}$ & $\mathbf{2 0 1 1}$ & $\mathbf{2 0 0 1}$ & $\mathbf{2 0 1 1}$ \\
\hline Los Alcázares & 670 & 671 & 3,2 & 3,1 \\
\hline San Javier & 1823 & 5109 & 6,1 & 12,9 \\
\hline San Pedro P. & 6717 & 2490 & 41,3 & 12,6 \\
\hline Torre Pacheco & 1783 & 7326 & 19,4 & 35,9 \\
\hline Comarca* & $\mathbf{1 0 9 9 3}$ & $\mathbf{1 5 5 9 6}$ & $\mathbf{1 4 , 4}$ & $\mathbf{1 5 , 4}$ \\
\hline Región Murcia & $\mathbf{9 5 5 8 9}$ & $\mathbf{1 2 9 1 1 7}$ & $\mathbf{1 6 , 1}$ & $\mathbf{1 6 , 6}$ \\
\hline
\end{tabular}

Fuente: Elaboración propia a partir de datos del INE.

Para el conjunto de la CCCMM las viviendas vacías representan el 15,4\% del total (Tabla 1). En el año 2001 el municipio con mayor porcentaje de viviendas vacías era San Pedro del Pinatar (41,3\%), seguido de Torre Pacheco (19,4\%); por el contrario en 2011 es Torre Pacheco, con un 35,9\%, el que posee la mayor cantidad de esta tipología de viviendas. Sin duda, los elevados valores de esta categoría de viviendas ponen de manifiesto la enorme cantidad de viviendas construidas en el periodo del boom inmobiliario y la escasa ocupación real de las mismas. Por lo general, las pérdidas económicas debido a su construcción han sido muy grandes (González Martín et al., 2012), pero aún lo han sido más las medioambientales, de las que apenas se habla.

A modo de resumen, en las figuras 5 y 6 se muestran los diferentes porcentajes de tipos de viviendas para los años 2001 y 2011. En el año 2001 las viviendas principales tenían un elevado porcentaje en Torre Pacheco y San Pedro del Pinatar. Las viviendas secundarías predominaban en los municipios ribereños al Mar Menor, Los Alcázares y San Javier.

En el año 2011 en los municipios de Los Alcázares, San Javier y San Pedro el número de viviendas vacías aumenta respecto a las principales, elevándose mucho el \% de viviendas vacías en Torre Pacheco. 
Figura 5

TIPOS DE VIVIENDAS (\%). AÑ̃ 2001

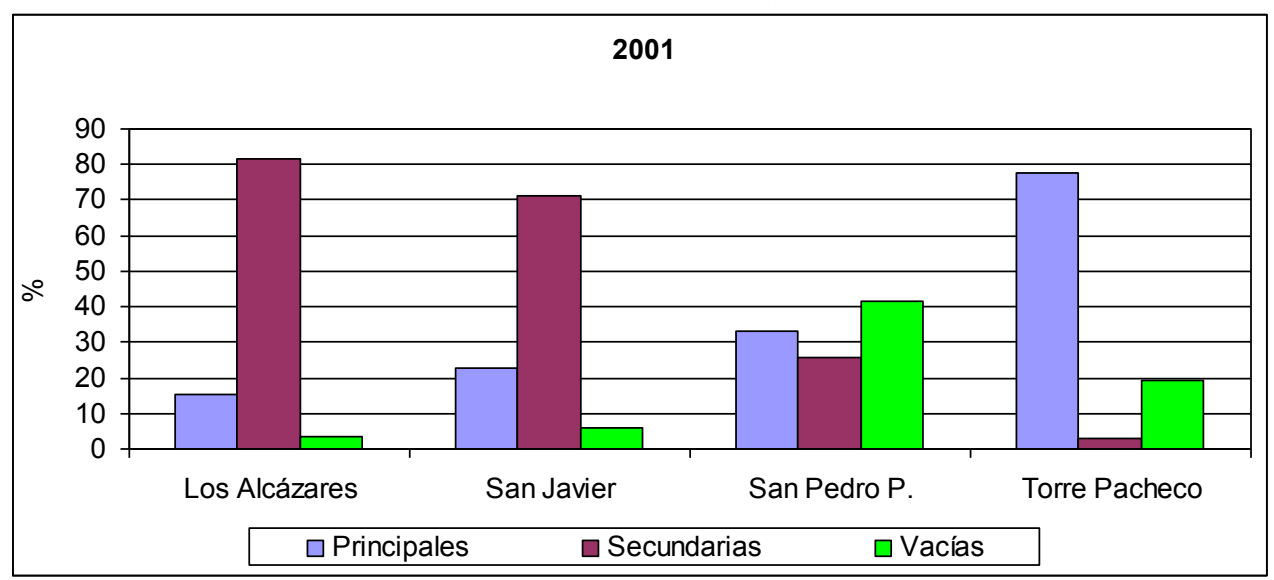

Fuente: elaboración propia a partir de datos el INE.

Figura 6

TIPOS DE VIVIENDAS (\%). AÑ̃ 2011

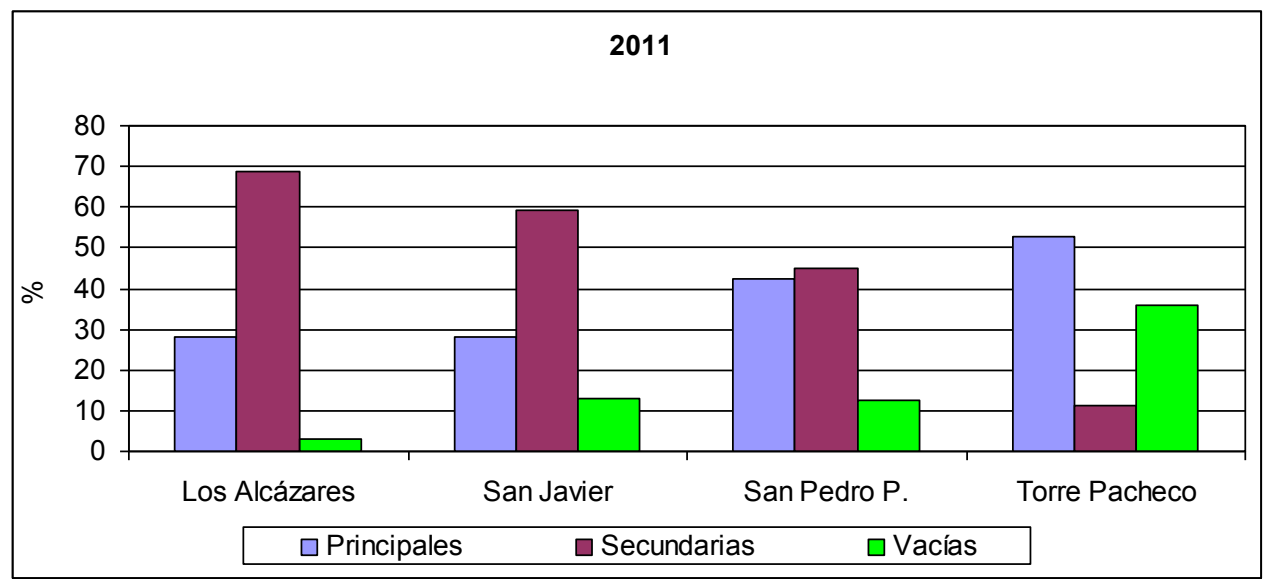

Fuente: elaboración propia a partir de datos el INE.

La diferencia de las viviendas secundarias y vacías entre los dos años censales (Figura 7) muestra como en todos los municipios a excepción de Los Alcázares de 2001 a 2011 las viviendas secundarias aumentan. Se da el caso de que muchas de las viviendas vacías son viviendas secundarias que debido a la crisis económica y por una mala planificación urbanística, basada en la especulación, aún siguen sin habitar, en especial en los extensos resort, construidos en torno a los numerosos campos de golf instalados en la CCCMM. 


\section{Figura 7 \\ DIFERENCIA DE VIVIENDAS SECUNDARIAS Y VACÍAS EN EL PERIODO 2001-2011}

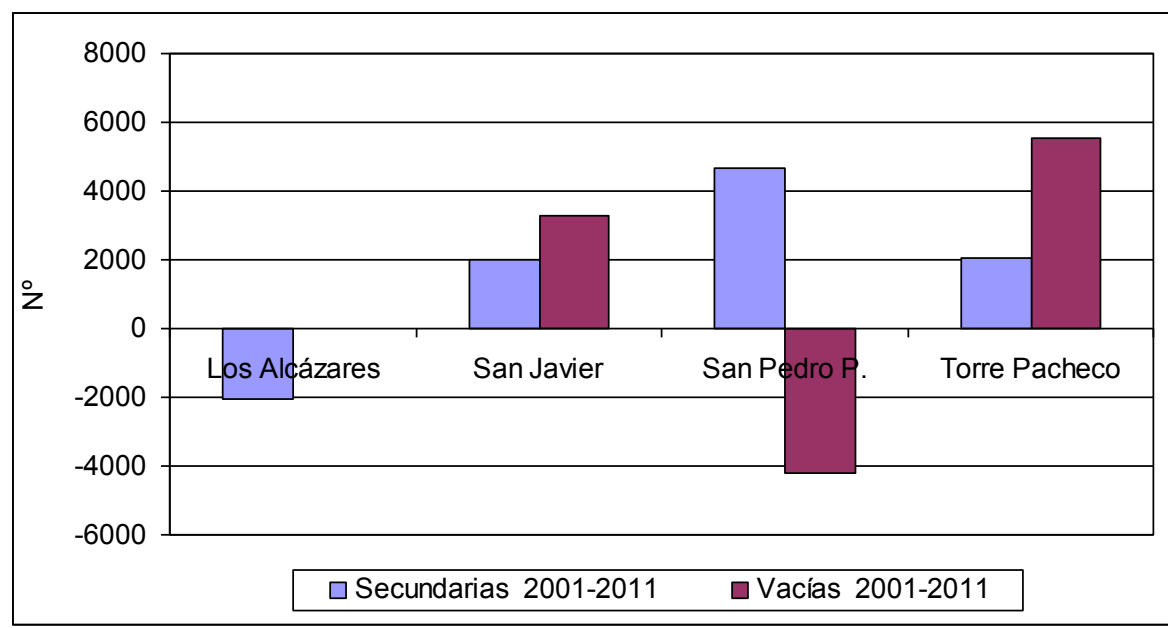

Fuente: elaboración propia a partir de datos el INE.

\subsubsection{Población}

Otro indicador de expansión urbana, es la población y su origen. En la figura 8 se muestra la evolución demográfica en los cuatro municipios principales de la CCCMM, exceptuando Murcia y Cartagena, cuyo volumen de población pudiera sesgar al de la comarca. En ella se observa un notable aumento en todos los municipios a partir de la década de los años setenta del siglo pasado y, en especial, en la década de los noventa. Este incremento, sin duda, está relacionado con la llegada de inmigrantes, tanto de trabajadores (para la construcción y el campo), como de personas que formarían parte del turismo residencial.

En el censo de 2011 el 15\% de la población en la CCCMM era extranjera (Tabla 2 y Figura 9), destacando Los Alcázares con un 38,2\%, Torre Pacheco y San Javier con valores cercanos al $30 \%$ y San Pedro del Pinatar con un $26 \%$.

Por lo que respecta a la procedencia de los extranjeros, por regla general los procedentes de África o América (América del Sur y Central) suelen emigrar a la comarca en busca de trabajo, en especial en el campo debido a la enorme transformación que la CCCMM ha experimentado con la llegada de las aguas del trasvase Tajo-Segura; por el contrario, los procedentes de países europeos son los que forman parte de esa fracción de migrantes que buscan instalarse en la comarca, por su bonanza climática y cercanía al mar. El porcentaje global en la comarca está entorno al 9\% de los inmigrantes extranjeros, siendo muy destacado en algunos municipios como Los Alcázares, en donde la población procedente de la Unión Europea representa casi el 16\% o en San Javier y en San Pedro del Pinatar el $10 \%$ (INE). 
Figura 8

EVOLUCIÓN DE LA POBLACIÓN EN LOS MUNICIPIOS DE LA CCCMM*

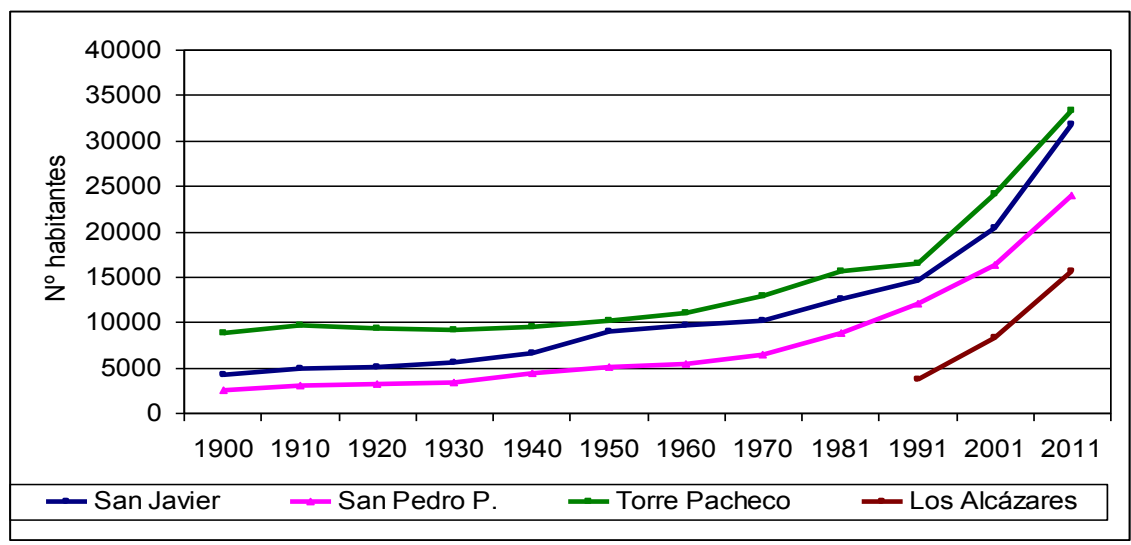

* excluidos los municipios de Cartagena y Murcia.

Fuente: elaboración propia a partir de datos del INE.

Tabla 2

TIPOS DE POBLACIÓN EN LA CCCMM (2011)

\begin{tabular}{|l|c|c|c|c|c|c|}
\hline \multicolumn{1}{|c|}{ Municipio } & $\begin{array}{c}\text { Población } \\
\text { Total }\end{array}$ & $\begin{array}{c}\text { Población } \\
\text { Española }\end{array}$ & $\begin{array}{c}\text { Población } \\
\text { Extranjera }\end{array}$ & $\begin{array}{c}\text { Extranjera } \\
\mathbf{\%}\end{array}$ & $\begin{array}{c}\text { Extranjera } \\
\text { EU }\end{array}$ & $\begin{array}{c}\text { Extranjeros } \\
\text { UE \% }\end{array}$ \\
\hline Los Alcázares & 15628 & 9654 & 5974 & 38,2 & 2459 & $\mathbf{1 5 , 7}$ \\
\hline San Javier & 31901 & 22794 & 9107 & 28,5 & 2815 & $\mathbf{8 , 8}$ \\
\hline San Pedro P. & 23981 & 17813 & 6169 & 25,8 & 2247 & $\mathbf{9 , 4}$ \\
\hline Torre Pacheco & 33419 & 23659 & 9761 & 29,2 & 1646 & $\mathbf{4 , 9}$ \\
\hline Comarca* & $\mathbf{1 0 4 9 2 9}$ & $\mathbf{7 3 9 2 0}$ & $\mathbf{3 1 0 1 1}$ & $\mathbf{2 9 , 5}$ & $\mathbf{9 1 6 7}$ & $\mathbf{8 , 7}$ \\
\hline
\end{tabular}

* excluidos los municipios de Cartagena y Murcia.

Fuente: elaboración propia a partir de datos del INE.

Respecto al total de extranjeros a nivel municipal (Tabla 3), los procedentes de la EU es en Los Alcázares, en donde se han asentado en mayor número (41,2\%), seguidos de San Pedro del Pinatar $(36,4 \%)$ y San Javier $(30,9 \%)$. Los africanos preferentemente se encuentran en Torre Pacheco y Cartagena y los inmigrantes de América del Sur y Central en Murcia y Torre Pacheco.

A nivel comarcal (Tabla 3), el mayor número de población extranjera presente en la comarca procede de Africa con un $40 \%$, seguida de americanos del Centro y Sur con un $22 \%$, y de la Unión Europea con un representativo 30\%. En el conjunto de otras nacionalidades (10\%) figuran, principalmente, migrantes de los países del Este y chinos. Sin duda, la población extranjera que mayor impacto produce atendiendo a la expansión urbana, es el grupo perteneciente a la Unión Europea (López Colás et al., 2007), que al tener mayor poder adquisitivo y demandar casas unifamiliares, ocasiona una mayor ocupación del suelo. 
Figura 9

NACIONALIDAD DE LA POBLACIÓN EN LA CCCMM (2011)

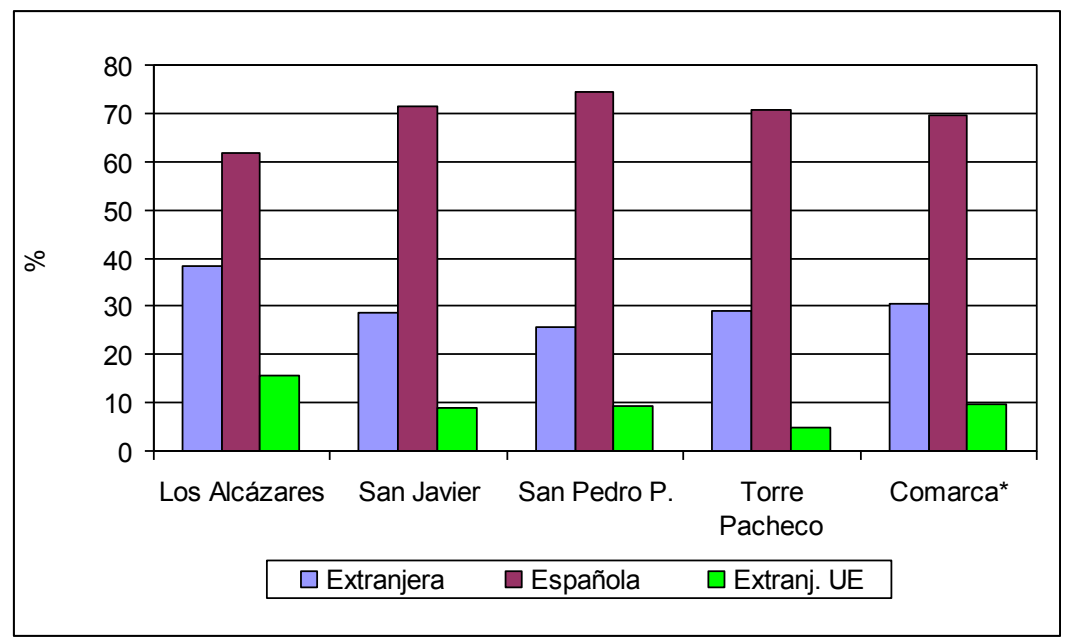

* excluidos los municipios de Cartagena y Murcia.

Fuente: elaboración propia a partir de datos del INE.

Tabla 3

ORIGEN DE LA POBLACIÓN EXTRANJERA

EN LOS MUNICIPIOS DE LA CCCMM

\begin{tabular}{|l|c|c|c|c|c|c|c|c|}
\hline \multicolumn{1}{|c|}{ Municipios } & EU & EU \% & África & África \% & América & América \% & Otros & Otros \% \\
\hline Los Alcázares & 2459 & 41,2 & 1472 & 24,6 & 1415 & 23,7 & 627 & 10,5 \\
\hline San Javier & 2815 & 30,9 & 3629 & 39,8 & 1894 & 20,8 & 770 & 8,5 \\
\hline San Pedro P. & 2247 & 36,4 & 2205 & 35,7 & 1090 & 17,7 & 627 & 10,2 \\
\hline Torre Pacheco & 1646 & 16,9 & 5112 & 52,4 & 2444 & 25,0 & 560 & 5,7 \\
\hline Comarca* & $\mathbf{9 1 6 7}$ & $\mathbf{2 9 , 6}$ & $\mathbf{1 2 4 1 8}$ & $\mathbf{4 0 , 0}$ & $\mathbf{6 8 4 3}$ & $\mathbf{2 2 , 1}$ & $\mathbf{2 5 8 4}$ & $\mathbf{8 , 3}$ \\
\hline
\end{tabular}

* excluidos los municipios de Cartagena y Murcia.

Fuente: Elaboración propia a partir de datos del INE.

\subsection{Evolución de la superficie urbanizada en la Comarca según digitalización.}

En primer lugar, hay que mencionar que para los municipios de Murcia y Cartagena tan sólo se han considerado las superficies incluidas en el área estudiada de la CCCMM y, por lo tanto, no figuran las superficies urbanizadas de sus grandes ciudades.

En la comarca, la evolución que la superficie urbanizada ha experimentado en el último medio siglo ha sido espectacular (Figura 10). De 8,2 $\mathrm{km}^{2}$ ascendió a 21,8 $\mathrm{km}^{2}$ en el año 1981 y a $88,5 \mathrm{~km}^{2}$ en el 2011. En porcentaje se ha pasado del $1 \%$ en 1956 , a un $2,7 \%$ en 1981 y al $11 \%$ en 2011 (Tabla 4). 
Para los tres años de referencia digitalizados, las diferencias en las superficies urbanizadas son muy notables para el primer periodo de 25 años, pero espectaculares en el segundo periodo de 30 años (Figura 11).

\section{Tabla 4}

\section{SUPERFICIE URBANIZADA EN LA CCCMM}

\begin{tabular}{|l|c|c|c|c|c|c|c|}
\hline \multirow{2}{*}{\multicolumn{1}{|c|}{ Municipio }} & Municipio & \multicolumn{2}{|c|}{$\mathbf{1 9 5 6}$} & \multicolumn{2}{c|}{$\mathbf{1 9 8 1}$} & \multicolumn{2}{c|}{$\mathbf{2 0 1 1}$} \\
\cline { 2 - 8 } & $\mathbf{k m}^{\mathbf{2}}$ & $\mathbf{k m}^{\mathbf{2}}$ & $\mathbf{\%}$ & $\mathbf{k m}^{\mathbf{2}}$ & $\mathbf{\%}$ & $\mathbf{k m}^{\mathbf{2}}$ & $\mathbf{\%}$ \\
\hline Los Alcázares & 19,8 & 0,5 & 2,5 & 1,7 & 8,6 & 7,7 & 38,8 \\
\hline Cartagena* & 198,5 & 2,7 & 1,4 & 7,1 & 3,6 & 20,2 & 10,2 \\
\hline Murcia* & 295,2 & 1,3 & 0,5 & 2,3 & 0,8 & 22,6 & 7,6 \\
\hline San Javier & 75,1 & 1,8 & 2,4 & 4,2 & 5,6 & 12,5 & 16,6 \\
\hline San Pedro & 22,3 & 0,5 & 2,2 & 2,4 & 10,8 & 6,0 & 26,6 \\
\hline Torre Pacheco & 189,4 & 1,4 & 0,7 & 4,0 & 2,1 & 19,4 & 10,2 \\
\hline Total Comarca & $\mathbf{8 0 0 , 3}$ & $\mathbf{8 , 2}$ & $\mathbf{1 , 0}$ & $\mathbf{2 1 , 7}$ & $\mathbf{2 , 7}$ & $\mathbf{8 8 , 4}$ & $\mathbf{1 1 , 0}$ \\
\hline
\end{tabular}

*Superficie del municipio en la comarca.

Fuente: elaboración propia.

Figura 10

\section{SUPERFICIE URBANIZADA DIGITALIZADA $\left(\mathrm{km}^{2}\right)$ EN LA CCCMM}

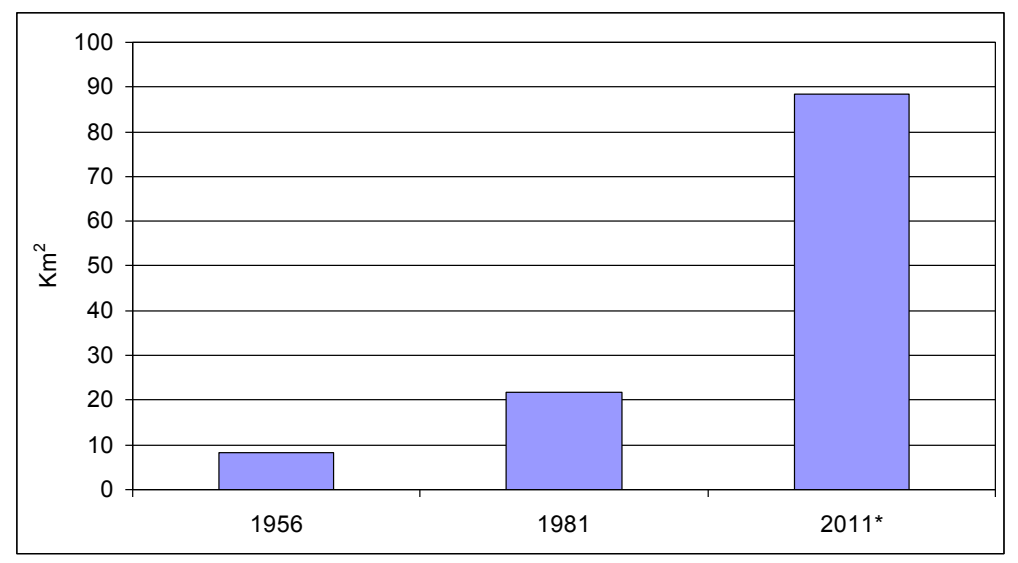

* Incluidos resorts

Fuente: elaboración propia.

A nivel municipal, casi todos los municipios muestran una evolución similar. Es de reseñar la notable variación existente entre los años 1981 y 2011 en todos los municipios. En valores absolutos (Figura 11) el que más superficie construida tiene en la actualidad es Murcia, seguido de Cartagena y Torre Pacheco. Por el contrario, en valores relativos destacan, especialmente, los dos municipios más pequeños de la comarca, Los Alcázares 
y San Pedro, por el alto porcentaje de superficie construida (Figura 12). En Los Alcázares representa casi un $40 \%$ y en San Pedro el 27\%. La superficie que en la comarca corresponde al municipio de Murcia es la que menos porcentaje de superficie urbanizada posee en 1956 y 1981, ascendiendo mucho en 2011 como consecuencia de las nuevas urbanizaciones y resorts que recientemente se han instalado allí.

\section{Figura 11}

\section{EVOLUCIÓN DE LA SUPERFICIE URBANIZADA DIGITALIZADA (KM²) EN LOS DIFERENTES MUNICIPIOS Y COMARCA.}

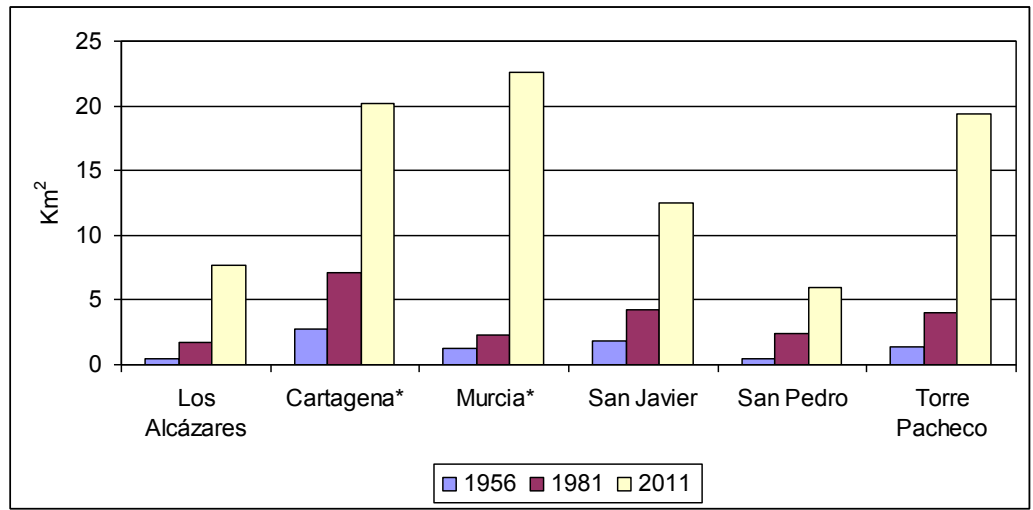

*Superficie del municipio en la comarca

Fuente elaboración propia.

Figura 12

\section{EVOLUCIÓN DE LA SUPERFICIE URBANIZADA DIGITALIZADA (\%) EN LOS DIFERENTES MUNICIPIOS}

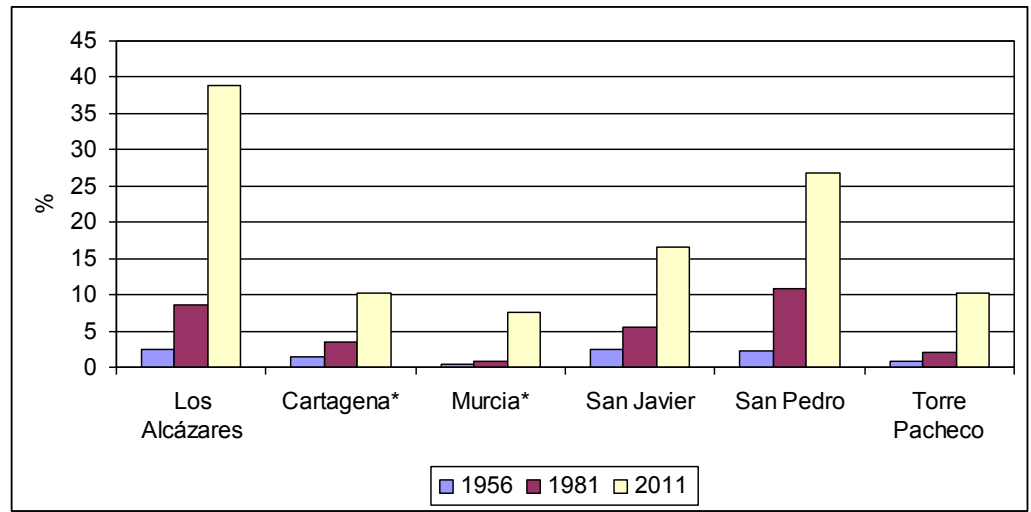

* Superficie del municipio en la comarca Fuente elaboración propia. 
A nivel espacial, en la figura 13 se puede observar la evolución de las superficies construidas y urbanizadas en los tres años de referencia digitalizados. Es de destacar la enorme concentración de superficie construida en la ribera norte del Mar Menor, correspondiente de norte a sur a los municipios de San Pedro del Pinatar, San Javier y Los Alcázares.

\section{Figura 13 \\ EVOLUCIÓN DE LA SUPERFICIE URBANIZADA EN LA CCCMM}

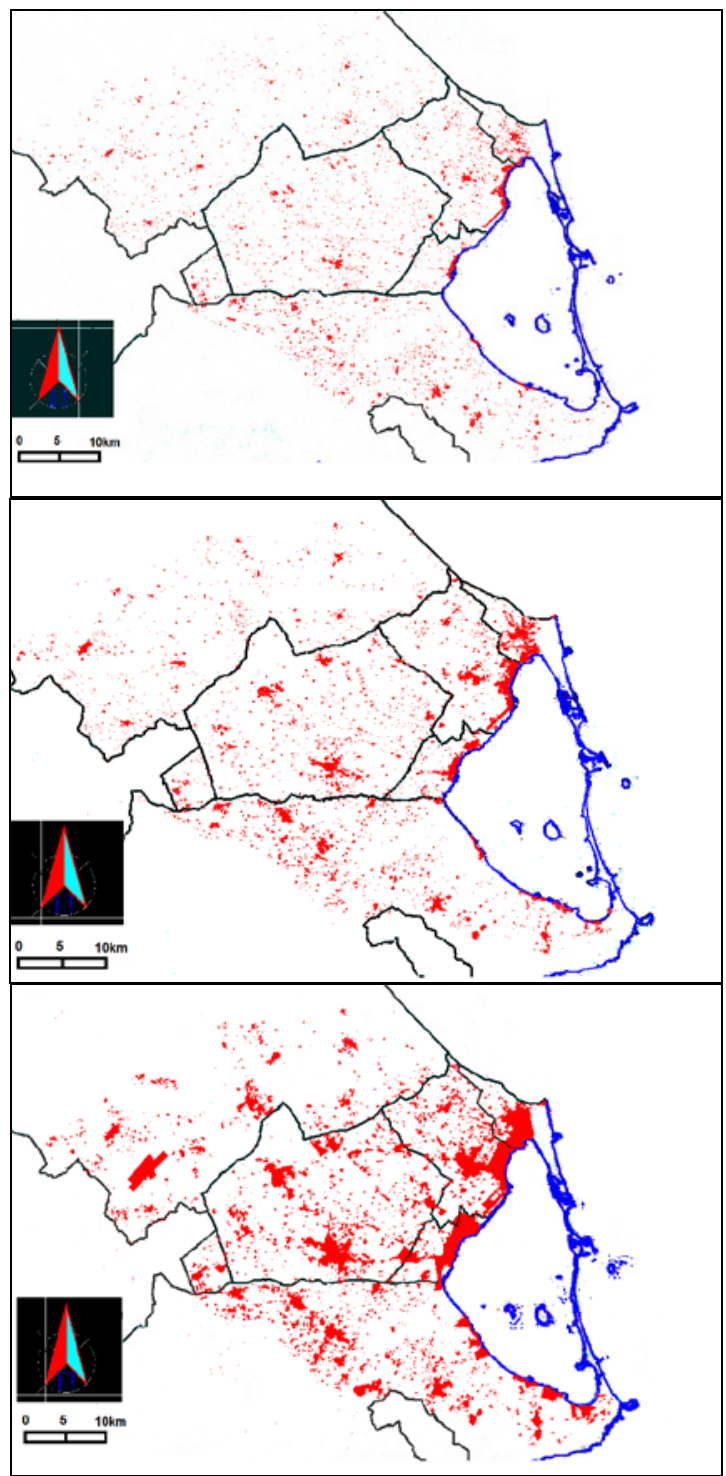

Imagen superior 1956; intermedia 1981; inferior 2011. Fuente: elaboración propia. 
En 1956 aparece una población dispersa en los diferentes municipios y se empieza a advertir una ligera concentración en las riberas del Mar Menor, en especial, en Los Alcázares y San Javier.

En 1981 se observa como todos núcleos principales de población incrementan la superficie construida. Aumenta de forma notable en la ribera norte del Mar Menor y se instalan nuevas urbanizaciones, de cierta entidad, en las tierras interiores.

En 2011 la expansión urbana es muy significativa. En la actualidad, en municipios como Los Alcázares el $40 \%$ de la superficie del municipio está urbanizada y en San Pedro del Pinar un tercio de la misma. En Torre Pacheco además de la expansión del núcleo principal de población aparecen nuevos espacios urbanizados, principalmente asociados a Resort y Campos de Golf. Esto mismo ocurre en los territorios de los municipios de Murcia y Cartagena pertenecientes a la CCCMM. La Ribera Norte del Mar Menor (al norte de la Rambla del Albujón) se encuentra totalmente urbanizada y las casas se suceden de manera continua hasta el límite con la Comunidad Autónoma vecina. En la Ribera Sur del Mar Menor, se han instalado también nuevas urbanizaciones en Los Urrutias, o Los Nietos, pero aún las casas no han cerrado del todo el perímetro, principalmente debido a que en esta área se encuentran diversos parajes naturales protegidos.

Consecuencia directa del incremento de las superficies urbanizadas es el aumento de las superficies de suelo selladas por esta causa. En 2011 las superficies de este tipo ocupaban $88,4 \mathrm{~km}^{2}$, lo que representa el $11 \%$ de la comarca.

\subsection{Vías de comunicación}

Las vías de comunicación constituyen otro de los elementos sellantes del suelo, especialmente las carreteras asfaltadas en sus diferentes tipologías. La actividad agrícola actual de la comarca con vocación exportadora y el incremento de la actividad turísticoresidencial ha hecho que el número de vías de comunicación aumente, al tiempo que a las antiguas se les ha incrementado su anchura por el mayor número de vehículos que transitan por ellas y el tamaño de los mismos.

Hasta 1984, en que se iniciaron los traspasos de competencias de las redes comarcales a las comunidades autónomas españolas, la red de transporte por carretera contaba con pocos kilómetros de vías principales cuyo trazado presentaba un franco objetivo de unión del área con la red concéntrica nacional a Madrid. La conexión interna y con las provincias limítrofes se realizaba por medio de vías antiguas y obsoletas que ya desde los años setenta daban muestra de su mal estado con la llegada de los primeros turistas extranjeros a la zona. Desde entonces, la red viaria de la CCCMM ha experimentado un fuerte impulso con la construcción de las primeras autovías, A-30, AP-7, RM-1, RM-2 y RM-19 que han sido capaces de minimizar el efecto de perificidad que soportaban con anterioridad a finales del S. XX, en el contexto general del Arco Mediterráneo (Serrano Martínez, 2007). Hay que subrayar también la importancia en la mejora realizada en el área de estudio en todas las carreteras de segundo y tercer orden que cierran el entramado de conexión interna entre las diferentes poblaciones.

Por otro lado, están las carreteras y viales construidos para el abastecimiento de las explotaciones agrarias y logística de sus productos. Con la llegada de las primeras aguas 
trasvasadas en los años ochenta, la red de caminos se densificó exponencialmente para cubrir estas necesidades y las propias de mantenimiento y gestión de los canales del post-trasvase o de distribución del agua. Las facilidades de movilidad proporcionadas por estas últimas, facilitaron el crecimiento de las explotaciones agrícolas y con ellas se fueron construyendo kilómetros de viales de tercera y cuarta categoría destinadas a la intercomunicación de esas explotaciones con las vías principales y con los centros de almacenaje y redistribución.

Todo ello ha hecho que, actualmente, la longitud total de las diferentes vías de comunicación que existen en la CCCMM, según los cálculos realizados, es de $4.297 \mathrm{~km}$, y considerando la anchura de cada tipo de vía, la superficie que ocupan es de $8 \mathrm{~km}^{2}$ (Tabla 5). Esta superficie se suma a la superficie de suelo sellada procedente de las superficies urbanizadas.

Por municipios, las áreas de Cartagena y Murcia que se incluyen en la comarca, junto con Torre Pacheco son los que más kilómetros de vías poseen. Como es lógico, se trata de los de mayor extensión. Por el contrario, los pequeños, San Pedro del Pinar y Los Alcázares, son los que tienen menores longitudes de vías.

Por último, en lo que se refiere a la densidad media de vías de comunicación en la comarca esta es de 5,4 km por $\mathrm{km}^{2}$ (Tabla 5). Los municipios con mayores valores de concentración son los más pequeños como Los Alcázares y San Pedro del Pinatar (Figura 14), 13,9 y $9,9 \mathrm{~km} / \mathrm{km}^{2}$ respectivamente. Si comparamos estos datos con la densidad vial media de España que es de $0,32 \mathrm{~km} / \mathrm{km}^{2}$ (Matellanes Ferreras, 2014), se constata como la de la CCCMM es muy alta. No obstante, hay que mencionar que la densidad de España está calculada teniendo en cuenta los $\mathrm{km}$ de autopistas, autovías y carreteras de $1^{\circ}, 2^{\circ}$ y $3^{\circ}$ orden y en nuestro análisis se han incluido también viales de $4^{\mathrm{a}}$ categoría.

Tabla 5

SUPERFICIE OCUPADA EN LA CCCMM POR LAS VÍAS DE COMUNICACIÓN

\begin{tabular}{|l|c|c|c|c|c|}
\hline Municipios & $\begin{array}{c}\text { Área } \\
\left(\mathbf{m}^{\mathbf{2}}\right)\end{array}$ & $\mathbf{\%}$ & $\begin{array}{c}\text { Longitud } \\
(\mathbf{K m})\end{array}$ & $\mathbf{\%}$ & $\begin{array}{c}\text { Densidad } \\
\left(\mathbf{k m} / \mathbf{k m}^{2}\right)\end{array}$ \\
\hline Los Alcázares & 570.817 & 7,2 & 275,5 & 6,4 & 13,9 \\
\hline San Javier & 1.293 .267 & 16,3 & 668,9 & 15,5 & 8,9 \\
\hline San Pedro del Pinatar & 412.906 & 5,2 & 221,3 & 5,1 & 9,9 \\
\hline Torre Pacheco & 1.862 .131 & 23,4 & $1.082,6$ & 25,1 & 5,7 \\
\hline Murcia* & 1.450 .701 & 18,3 & 921,5 & 21,4 & 3,1 \\
\hline Cartagena* & 2.336 .121 & 29,4 & $1.127,5$ & 26,2 & 5,6 \\
\hline TOTAL & $\mathbf{7 . 9 2 5 . 9 4 3}$ & & $\mathbf{4 . 2 9 7 , 3}$ & & $\mathbf{5 , 4}$ \\
\hline
\end{tabular}

* Sólo se considera la superficie del municipio incluida en la comarca.

Fuente: Elaboración propia a partir de datos de OSM. 


\section{Figura 14 \\ VÍAS DE COMUNICACIÓN EN LA COMARCA}

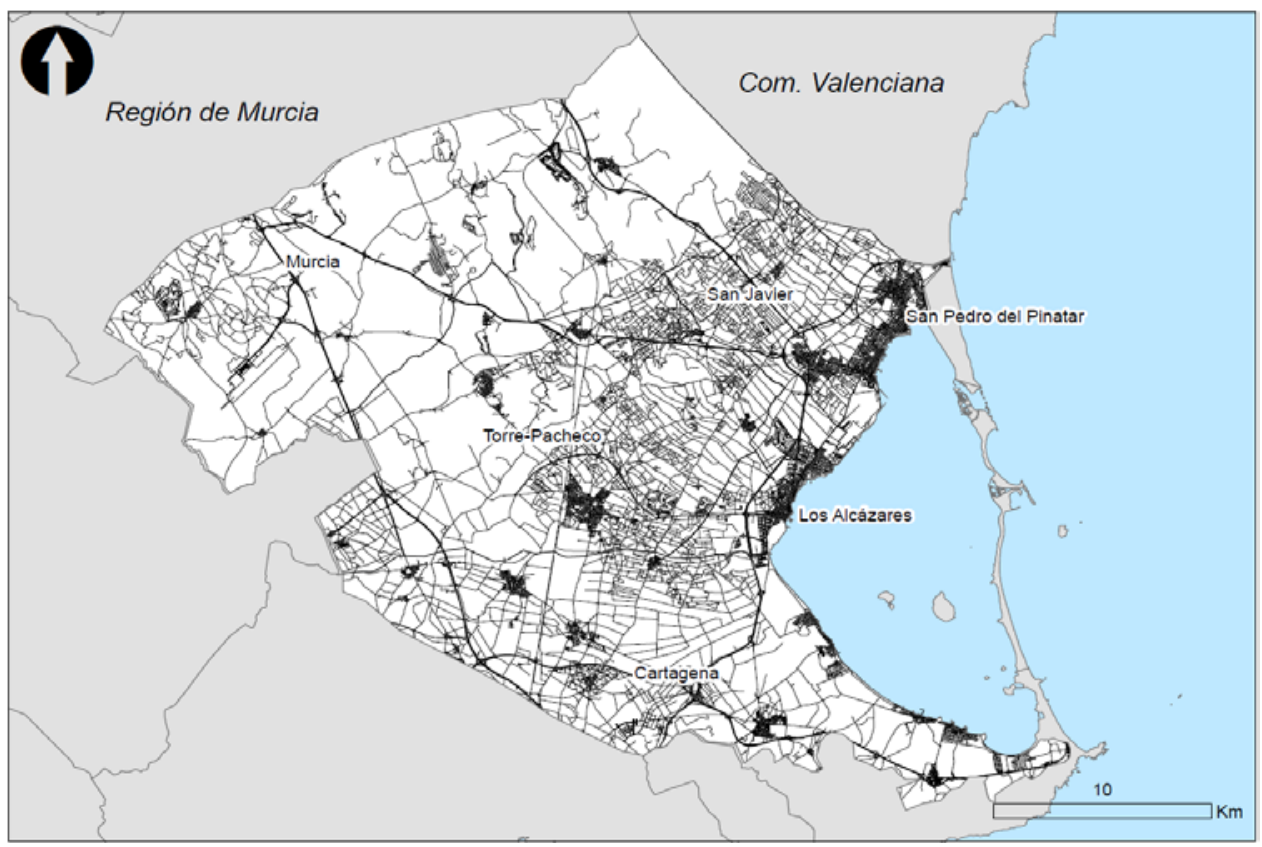

Fuente: elaboración propia a partir de datos de OSM.

\subsection{Riesgo de inundaciones por efectos del sellado del suelo}

Uno de los efectos directos que tiene el aumento de superficies impermeabilizadas es el sellado del suelo y, como consecuencia, el aumento de la superficie inundable en determinadas áreas.

Si se tiene en cuenta que la superficie digitalizada urbanizada asciende a $88,4 \mathrm{~km}^{2}$ y la de la red viaria a 7,9 $\mathrm{km}^{2}$, se alcanza un total de $96,3 \mathrm{~km}^{2}$. Esta superficie en relación con la de la comarca estudiada $\left(776,45 \mathrm{~km}^{2}\right)$, representa el nada despreciable $12,4 \%$ de sellado. Y más aún, si a este total se le suma la ocupada por invernaderos, que también son ámbitos espaciales artificiales impermeabilizados, y que se han visto aumentados en los últimos años, especialmente en el litoral de la Región de Murcia (OSE 2006), y en particular en la comarca aquí analizada (Romero Díaz et al., 2011, Caballero Pedraza et al., 2015), hace que el riesgo de inundación se haya visto incrementado y que la CCCMM sufra de forma recurrente los efectos de las avenidas (Romero Díaz et el., 2010).

Para comprobar el efecto de las superficies selladas en las inundaciones se ha realizado un análisis del número de inmuebles construidos en zona inundable según diferentes periodos de retorno (PR10, PR50, PR100 y PR500). El crecimiento acumulado en el litoral de la CCCMM supera las 13.778 edificaciones, lo que representa un total de 8,5 $\mathrm{km}^{2}$ (PR500) (Figura 15). 
De todo lo construido, los municipios de Cartagena, Torre-Pacheco, San Javier y Los Alcázares, por ese orden, se dividen el $90 \%$ de lo construido en zona inundable hasta el momento presente. San Pedro del Pinatar y la parte interviniente en el área de estudio del término municipal de Murcia apenas contribuyen a ello, puesto que, pese a que han registrado también crecimientos notables, el primer caso se localiza sobre una zona topográficamente elevada que la mantiene alejada de zonas potencialmente inundables y, en el segundo, la superficie de este municipio que corresponde a la comarca, se localiza en la cabecera de la red drenaje del área de estudio y los fenómenos de desbordamiento y avenida aquí no alcanzan superficies considerables, como sí sucede con los municipios aguas abajo.

\section{Figura 15 \\ SUPERFICIE URBANIZADA EN LA CCCMM Y ZONAS INUNDABLES (PR500)}

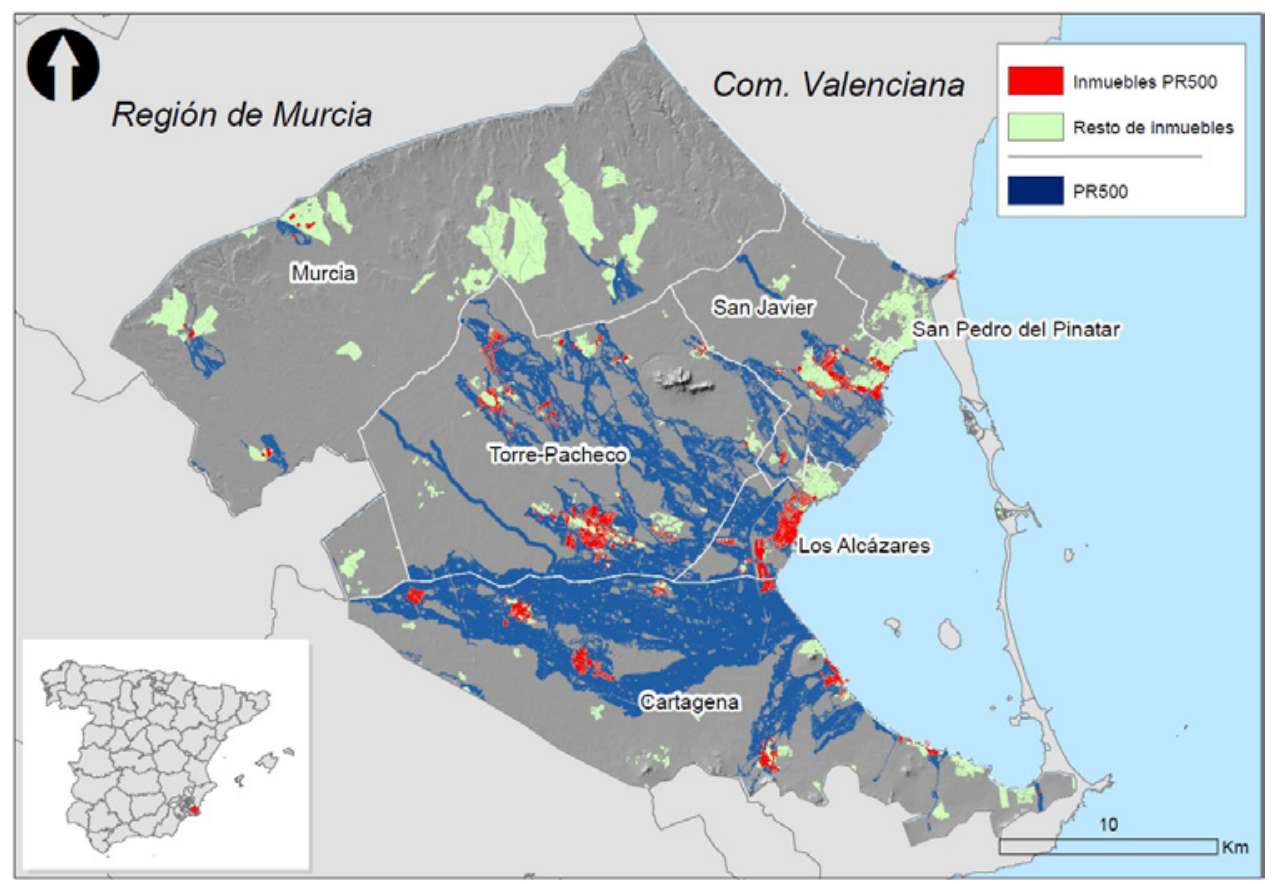

Fuente: Pérez Morales et al., 2016.

El análisis desglosado en cifras relativas revela unos resultados de gran relevancia para dar idea sobre el problema de las inundaciones. Las parcelas catastrales contempladas representan el 29,9\% con respecto al total, y su superficie expuesta es del 18,8\%. Llama la atención como el aumento de dichas parcelas en áreas propensas a experimentar inundaciones ha sido mayor porcentualmente en la zonas inundables del PR10, precisamente, la más comúnmente afectada. Se trata de un dato que evidencia un serio problema 
de negligencia institucional, pero que además de eso, resulta de un comportamiento habitual en un ámbito geográfico donde la red hidrográfica está compuesta en su mayoría por ramblas y barrancos, que de forma natural permanecen secos durante largos periodos de tiempo. Esto contribuye a una percepción baja del peligro de inundación (Llasat et al., 2008) y, desafortunadamente, invita desde siempre a ocupar las márgenes más próximas a los lechos de inundación, e incluso, a instalar las edificaciones directamente en el fondo de esos cauces fluviales y desdibujar por completo el trazado original de los mismos (Belmonte Serrato et al., 2011).

El comportamiento municipal en términos absolutos concuerda con el tamaño de los mismos. Sin embargo, se advierten diferentes patrones que merecen ser señalados. En el caso de Torre-Pacheco, de un lado, estarían las viviendas que de forma tradicional han ido ocupando el campo para el aprovechamiento agrario y, de otro, los nuevos crecimientos urbanísticos asociados al fenómeno turístico de los resort. En ambos, un número importante de las edificaciones son afectadas potencialmente por las inundaciones debido a un efecto combinado de: (i) el sellado y su repercusión sobre el aumento de la escorrentía y superficie inundable, y (ii) una alteración del trazado de la red de drenaje hasta el extremo de su desaparición con la consecuente ocupación y aumento de la exposición. Los ejemplos concretos son numerosos y se repiten a lo largo de los diferentes tramos de los cursos fluviales del área de estudio. Los más evidentes se sitúan en los tramos medios y bajos, próximos a la desembocadura, donde la presión urbanística es más intensa. Por citar alguno especialmente problemático al haber sido usurpado gran parte de su trazado sería el de la rambla del Albujón con desembocadura en el saturado núcleo urbano de Los Alcázares.

Figura 16

SUPERFICIE CONSTRUIDA EN ZONAS INUNDABLES PARA LOS PERIODOS DE RETORNO 10, 50, 100 Y 500 AÑOS

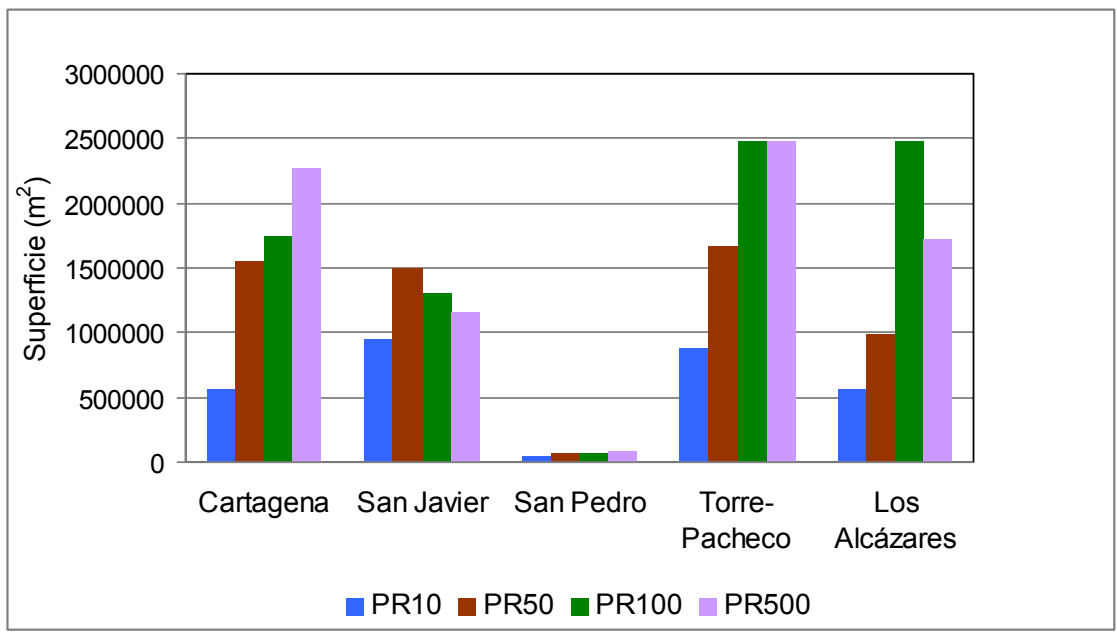

Fuente Pérez Morales et al., 2016. 


\section{CONCLUSIONES}

Consecuencia del "Boom inmobiliario" (1998-2007) y del incremento de la actividad turística, en la CCCMM ha tenido lugar un espectacular incremento de la superficie urbanizada. Ello fue debido, por un lado, a las condiciones de bonanza climática que se dan en la comarca y su cercanía al Mar Menor y, por otro, al precio bajo del dinero en esos años y a una legislación urbanística y de ordenación territorial expansionista, que incentivó este tipo de desarrollo para beneficiarse de ese capital fijo liberado (Harrison, 2006; Gaja, 2008; Burriel, 2008; Jiménez, 2009).

Para comprobar esta expansión urbana y su relación con el turismo se ha analizado, por un lado, la tipología de viviendas construidas y, por otro, la población existente y su procedencia. Respecto al tipo de viviendas se ha observado especialmente la evolución y número de las de segunda residencia y vacías. La mayoría de las viviendas secundarias son ocupadas por turistas procedentes de otros puntos de la Región de Murcia, de España o de población extranjera. Por municipios destaca Los Alcázares, en donde, en 2011, el 70\% de sus viviendas eran de esta tipología, seguido de San Javier con un $59 \%$. Si se consideran las construidas y vacías en la actualidad, sobresale Torre Pacheco con un $36 \%$.

Respecto a la población, es de destacar el incremento poblacional que tuvo lugar en la década de los años noventa del siglo pasado (ligada no sólo al turismo sino también a la creciente actividad económica de la comarca). La población extranjera representa en la CCCMM el 30\% de la población total y en algunos municipios como Los Alcázares, supera el $38 \%$. Respecto a la actividad turística interesa especialmente conocer la población extranjera que procede de la Unión Europea, siendo esta de un $9 \%$ en la comarca, pero del $16 \%$ en Los Alcázares. Este colectivo de población demanda casas unifamiliares en áreas periurbanas o en urbanizaciones específicas tipo Resort, que para su construcción es necesario utilizar grandes extensiones de terreno.

La digitalización de las áreas construidas en tres fechas (1956, 1981 y 2011) ha mostrado un incremento notable de 1956 a 1981, pero espectacular de 1981 a 2011. Se ha pasado de 8,2 km² construidos en 1957 a $21,7 \mathrm{~km}^{2}$ en 1981 y a $88,4 \mathrm{~km}^{2}$ en el año 2011 . En Los Alcázares la superficie construida representa el $40 \%$ y en San Pedro casi el 30\%.

Por otra parte, las vías de comunicación también han experimentado una mejora e incremento, muy sustancial, consecuencia de la actual actividad agraria de carácter intensivo y la actividad turística. La longitud total de la red viaria en la CCCMM es de $4.297 \mathrm{~km}$, que ocupa una superficie de casi $8 \mathrm{~km}^{2}$, con una densidad media de 5,4 $\mathrm{km} / \mathrm{km}^{2}$.

Derivado de la construcción de viviendas y urbanizaciones, junto al desarrollo de diversas infraestructuras asociadas, como son las vías de comunicación, en la comarca ha tenido lugar un sellado artificial del suelo muy importante. La superficie de suelo sellada, si se tiene en cuenta la total construida $\left(88,4 \mathrm{~km}^{2}\right)$ y la red viaria $\left(7,92 \mathrm{~km}^{2}\right)$ es de 96,3 $\mathrm{km}^{2}$. No obstante, si se incluye la superficie de invernaderos, que constituyen igualmente espacios impermeabilizados, estimada según Caballero Pedraza et al. (2015) en 30,32 km², la superficie total sellada en la CCCMN asciende a 126,64 $\mathrm{km}^{2}$. En términos relativos el sellado del suelo comarcal representa el 16,3\% de la superficie. Esta, sin duda, refleja una 
alta proporción de suelo sellado e impermeabilizado, que evita la infiltración del agua en el suelo y, por el contrario, favorece las escorrentías y la generación de inundaciones cuando se producen lluvias de alta intensidad horaria.

$\mathrm{Al}$ relacionar las superficies construidas con las áreas inundables para diferentes periodos de retorno, se ha puesto de manifiesto como una amplia superficie de la comarca puede ser afectada por inundaciones, como así ha ocurrido en numerosas ocasiones (Romero Díaz et al., 2010, 2011). Ello es debido a las alteraciones que el hombre ha hecho en los diferentes cursos de agua. En ocasiones, al urbanizar casi toda la ribera del Mar Menor, las numerosas ramblas que vierten al Mar Menor han sido integradas en los callejeros urbanos, por lo que ante lluvias intensas suelen convertirse en verdaderos ríos, con efectos catastróficos para la población. En otros casos, lo que se ha alterado han sido las cabeceras de las cuencas vertientes al impermeabilizarlas por construcciones y viales, dando como resultado un aumento de caudal de las ramblas ya desde su inicio.

En definitiva, este estudio pone de manifiesto las interferencias negativas que los cambios de usos del suelo han producido en la comarca, y como el sellado del suelo, tanto por construcciones como por incremento de las vías de comunicación o construcción de invernaderos, incrementa el riesgo de sufrir inundaciones. Sin duda, las administraciones que gestionan el territorio no han actuado de manera adecuada y, por el contrario, han incrementando el riesgo de gran parte de la población que habita aquí, en especial, en las poblaciones ribereñas al Mar Menor.

\section{REFERENCIAS BIBLIOGRÁFICAS}

ALEDO, A., MAZÓN, T. y MANTECÓN, A. (2007): "La insostenibilidad del turismo residencial". Antropología y turismo: claves culturales y disciplinares., pp. 185-208. BELMONTE SERRATO, F., ROMERO DÍAZ, A., RUPÉREZ TIRADO, E. y MORENO BROTONS, J. (2011): “El impacto de la agricultura intensiva en el uso turístico de las playas de Marina de Cope (Murcia)", Cuadernos de Turismo, n 27, pp. 23-38.

BURRIEL, E.L. (2008). "La década prodigiosa del urbanismo español (1997-2006)". Scripta Nova, vol. XII, no 270 (64). On line: http://www.ub.edu/geocrit/sn/sn-270/ sn-270-64.htm

CASADO, M.A. (2006): "Retiring to Spain: An Analysis of Differences among North European Nationals", Journal of Ethnic and Migration Studies, vol. 32 (8), pp. 1.3211.339 .

CABALlERO PEDRAZA, A., ROMERO DÍAZ, A. y SOTO ESPINOSA, I. (2015): "Cambios paisajísticos y efectos medioambientales debidos a la agricultura intensiva en la Comarca del Campo de Cartagena-Mar Menor (Murcia)". Estudios geográficos Vol. LXXVI, 279: 473-498.

CREM (varios años). Anuarios estadísticos de la Región de Murcia. Centro Regional de Estadística de Murcia. On line: http://www.carm.es/econet/

CRESPÍ, S.N., PÉREZ-MARTÍNEZ, M., CUESTA, M.J., CABRERA, J.A., GARCÍA, A., y MILLÁN, R. (2007): Procesos de Degradación del Suelo. CIEMAT. Ministerio de Educación y Ciencia. 
DOCAMPO CALVO, A.M. (2011): Compactación, sellado y pérdida de suelos agrícolas en el campo de Cartagena a consecuencia de la expansión urbana. TFC en Ciencias Ambientales. Facultad de Biología.

GAJA, F. (2008): “El «tsunami urbanizador» en el litoral mediterráneo. El ciclo de hiperproducción inmobiliaria 1996-2006”, Scripta Nova, vol. VIII, n 270 (66). On line: http://www.ub.es/geocrit/sn/sn-270/sn-270-66.htm.

GARCÍA SÁNCHEZ, A., ARTAL TUR, A. y RAMOS PARREÑO, J.M. (2002): “El turismo del Mar Menor: predominio de la segunda residencia”, Cuadernos de Turismo, $\mathrm{n}^{\circ}$ 9, pp. 33-43.

GONZALEZ MARTÍN, B., PUMARES FERNÁNDEZ, P. y ROJAS TEJADA, A.J. (2012): "El impacto de la crisis de la construcción en las relaciones intergrupales dentro del sector". Gazeta de Antropología, vol. 28 (2), artículo 02 · http://hdl.handle. net/10481/21962.

GONZÁLEZ ORTIZ, J. L. (2007): “Comarca de Cartagena - Mar Menor”, en A. Romero Díaz y F. Alonso Sarría (Coords.) Atlas Global de la Región de Murcia. La Verdad CMM S.A., pp. 478-489.

HARRISON, J. (2006): "Economic crisis and democratic consolidation in Spain, 197382", Working Papers in Economic History, vol. 06 (10), 1-33.

HUETE, R. (2009): Turistas que llegan para quedarse. Una explicación sociológica sobre la movilidad residencial. Alicante, Universidad de Alicante.

HUETE, R. y MANTECÓN, A. (2013): "La migración residencial de noreuropeos en España”. Convergencia. Revista de Ciencias Sociales, vol. 20, (61), pp. 219-245, Universidad Autónoma del Estado de México.

IGN (Instituto Geográfico Nacional) (2006): SIOSE. Manual de fotointerpretación. Madrid. Ministerio de Fomento. On line: http://www.ign.es/siose/Documentacion/ Guia_Tecnica_SIOSE/070322_Manual_Fotointerpretacion_SIOSE_v1_2.pdf.

INE. Instituto Nacional de Estadística. On line: http://www.ine.es/

INE (2013). Notas de Prensa. Censos de Población y Viviendas 2011. Instituto Nacional de Estadística.

JIMÉNEZ, F. (2009): "Building boom and political corruption in Spain". South European Society and Politics, 14 (3), pp. 255-272.

KING, R., WARNES, A. y WILLIAMS, A.M. (2000): Sunset Lives: British Retirement Migration to the Mediterranean. Oxford. Berg

LLASAT, M. C., LÓPEZ, L., BARNOLAS, M. y LLASAT-BOTIJA, M. (2008): "Flashfloods in Catalonia: the social perception in a context of changing vulnerability", $A d v$. Geosci., vol.17, pp.63-70.

LOPEZ COLAS, J., MÓDENES CABRERIZO, J.A. y YÉPEZ MARTÍNEZ, B. (2007): "Los usuarios de residencias secundarias en España: perfiles regionales", Boletín de la Asociación de Geógrafos Españoles, n 45, pp. 307-325.

MARTÍNEZ MENCHÓN, M. y SENENT ALONSO, M. (2007): "El agua en el Campo de Cartagena", Revista Murciana de Antropología, no 14, pp. 47-61.

MATELLANES FERRERAS, R. (2014): "Infraestructuras de comunicación: Densidad vial por municipios”. On line: http://geoinnova.org/blog-territorio/infraestructuras-decomunicacion-densidad-viaria-por-municipio/ 
MAZÓN, T., HUETE, R. y MANTECÓN, A. (Ed.) (2009): Turismo, urbanización y estilos de vida. Las nuevas formas de movilidad residencial. Barcelona. Icaria.

MEMBRADO TENA, J.C. (2015): "Migración residencial y urbanismo expansivo en el Mediterráneo español", Cuadernos de Turismo, no 35, pp. 259-285.

MMA (2006): Perfil Ambiental de España 2005. Informe basado en indicadores. Madrid: Ministerio de Medio Ambiente, Centro de Publicaciones. 297 pp.

O’REILLY, K. (2009): "Migración intraeuropea y cohesión social: el grado y la naturaleza de la integración de los migrantes británicos en España”, en Turismo, urbanización y estilos de vida. Las nuevas formas de movilidad residencial (Mazón, T., Huete, R., y Mantecón, A., Ed.). Barcelona, Icaria.

OSE (2006): Cambios de Ocupación del Suelo en España: Implicaciones para la Sostenibilidad. Observatorio de la Sostenibilidad en España. On line:

http://www.upv.es/contenidos/CAMUNISO/info/U0637086.PDF. (Verificada: 01/09/2015)

PÉREZ MORALES, A., GIL GUIRADO, S. y OLCINA CANTOS, J. (2015): "Housing bubbles and the increase of flood exposure. Failures in flood risk management on the Spanish south eastern coast (1975-2013)". Journal of Flood Risk Management. PÉREZ MORALES, A., ROMERO DÍAZ, A. y CABALLERO PEDRAZA, A. (2016): "Urbanization process and its influence in the increase in flooding (Region of Murcia, Campo de Cartagena-Mar Menor, Southeast Spain)". Aportación del Comité Español de la Unión Geográfica International. The 33th International Geographical Congress. IGU, Beijing, 2016 (en prensa)

RODRÍGUEZ, V., CASADO, M.A. y HUBER, A. (Ed.) (2005): La migración de europeos retirados en España. Madrid, Consejo Superior de Investigaciones Científicas.

ROMAN CERVANTES, C. (2007): "El control del agua: tecnología y sistemas de extracción hidráulica en la comarca del Campo de Cartagena, 1880-1980”, Revista Murciana de Antropología, no 14, pp. 127-141.

ROMERO, J. (2010): “Construcción residencial y gobierno del territorio en España. De la burbuja inmobiliaria a la recesión”, Cuadernos Geográficos de la Universidad de Granada, no 47, pp. 17-46.

ROMERO DÍAZ, A., BELMONTE SERRATO, F., RUIZ SINOGA, J.D. y PÉREZ CORREAS, J.D. (2010): "Episodio de lluvias torrenciales del 27-28 de septiembre de 2009. Las inundaciones del campo de Cartagena (Murcia)". II Jornades de Meteorología i Climatología de la Mediterrània Occidental. Valencia.

ROMERO DÍAZ, A. y BELMONTE SERRATO, F. (2011): "El Campo de Cartagena una visión global”. En J. Hernández Bastida (Coord.) Recorridos por el Campo de Cartagena. Control de la degradación y uso sostenible del suelo. Instituto Mediterráneo del Agua, Murcia, pp. 17-48.

ROMERO DÍAZ, A., BELMONTE SERRATO., DO CAMPO CALVO, A. M. y RUÍZ SINOGA, J.D. (2011): “Consecuencias del sellado de los suelos en el Campo de Cartagena (Murcia)". En Gonzálvez Pérez, V y Marco Molina, J.A. (Eds.) Urbanismo expansivo de la utopía a la realidad. Univ. Alicante, pp. 605-616.

RULLAN, O. (2011): "Urbanismo expansivo en el Estado Español: de la utopía a la realidad", en Geografía: retos ambientales y territoriales. XXII Congreso de Geógrafos Españoles, Alicante, Universidad de Alicante y Asociación de Geógrafos Españoles, pp. 165-201. 
SERRANO MARTÍNEZ, J.M. (2007): “El transporte y las vías de comunicación”. En A. Romero Díaz y F. Alonso Sarria (Coords.) Atlas Global de la Región de Murcia. La Verdad - CMM S.A., pp. 376-383.

VERA REBOLLO, J.F. (2006): “Agua y modelo de desarrollo turístico: la necesidad de nuevos criterios para la gestión de los recursos". Boletín de la Asociación de Geógrafos Españoles, n. 42, pp. 155-178.

WILliAMS, A., KING, R., WARNES, A. y PATTERSON, G. (2000): "Tourism and Inter national Retirement Migration: New Forms of an Old Relationship in Southern Europe", Tourism Geographies, vol. 2 (1), pp. 28-49. 